\title{
For a Better Coordination Between Students Learning Styles and Instructors Teaching Styles
}

\author{
Sylvia Encheva \\ Stord/Haugesund University College \\ Bjørnsonsg. 45, \\ 5528 Haugesund, \\ Norway
}

\begin{abstract}
While learning has been in the main focus of a number of educators and researches, instructors' teaching styles have received considerably less attention. When it comes to dependencies between learning styles and teaching styles the available knowledge is even less. There is a definite need for a systematic approach while looking for such dependencies. We propose application of refinement orders and relational concept analysis for pursuing further investigations on the matter.
\end{abstract}

Keywords-Refinement orders; Relational concept analysis; Learning

\section{INTRODUCTION}

Learning styles [7] in general refer to how people learn. In [18] they are described as - visual, aural, verbal, physical, logical, social and solitary. Students' learning styles in particular have been wildly discussed and structured in a number of models, [18]. According to Felder and Soloman's model [4] learners can be: active or reflective, depending on their tendencies to retain and understand information; sensing or intuitive, depending on whether they prefer learning facts or discover possibilities and relationships; visual or verbal, depending on their preferences to information been presented visually and verbally; sequential or global, depending on whether they are more comfortable gaining understanding in linear steps or in large jumps. Instructional methods for coping with different learning styles are also included.

The importance of addressing most common learning styles is emphasized in [5]. Students, whose learning styles are compatible with the teaching style of a course instructor tend to retain information longer, apply it more effectively, and have more positive post-course attitudes toward the subject than do their counterparts who experience learning/teaching style mismatches, [5]. It is pointed that students also differ in their preferences to the way presented information is organized: inductive - where facts and observations are given, and underlying principles are inferred, or deductive - where principles are given, consequences and applications are deduced. Strengths and weakness of different learning styles are further discussed and a multi style approach is recommended.

"If professors teach exclusively in a manner that favours their students' less preferred learning style modes, the students' discomfort level may be great enough to interfere with their learning. On the other hand, if professors teach exclusively in their students' preferred modes, the students may not develop the mental dexterity they need to reach their potential for achievement in school and as professionals.", [6].

The Myers-Briggs Type Indicator model [14] is mainly concerned with students' preferences from psychological point of view. They can be extraverts or introverts, sensors or intuitors, thinkers or feelers, judgers or perceivers. This leads to sixteen different learning style types, [14].

The Kolb's model is based on students' preferences for how to take information in and how to internalize information, [15]. The model consists of four types of learners concrete, reflective; abstract, reflective; abstract, active or concrete, active.

The Herrmann Brain Dominance Instrument model is concerned with preferences based on some brain functions, [12]. The four modes are analysis; methods and procedures; teamwork and communications; creative problem solving, systems thinking, synthesis, and design.

Learner-centered and teacher-centered teaching styles are discussed in [1].

Five teaching styles are described in [9] - expert, formal authority, personal model, facilitator, and delegator. Their advantages and disadvantages are also clearly formulated. Four teaching styles are identified in [19] - formal authority, demonstrator, facilitator, and delegator.

Our goal is to find a systematic way for detecting between students learning styles and lecturers teaching styles applying permutographs, [2] and relational concept analysis (RCA), [13], [10].

\section{PRELIMINARIES}

Let $P$ be a non-empty ordered set. If $\sup \{x, y\}$ and inf $\{x, y\}$ exist for all $x, y \in P$, then $P$ is called a lattice [3]. In a lattice, illustrating partial ordering of knowledge values, the logical conjunction is identified with the meet operation and the logical disjunction with the join operation, [8].

Definition 1: [2] The permutograph on a set $X$ is the graph, denoted by $\Sigma_{X}$, whose set of vertices is the set $\mathcal{L}_{X}$ of linear orders on $X$ and whose edges are defined by the following adjacency relation, denoted $A d j$, between two linear orders: for $L, L^{\prime} \in \mathcal{L}_{X}, L A d j L^{\prime}$ if $\left|L \cap L^{\prime d}\right|=1$.

For two linear orders $L$ and $L^{\prime}$ on $X$ representing preferences, $d\left(L, L^{\prime}\right)=\left|L \cap L^{\prime d}\right|=\left|L \backslash L^{\prime}\right|$ is the number of disagreements on preferences between these two orders, [2]. 
The geodesic distance $\delta\left(L, L^{\prime}\right)$ between two linear orders $L$ and $L^{\prime}$ in a permutograph is the minimum number of commutations to carry out in order to go from one to the other, [2].

In RCA, input data is organized as a pair made of a set of objects-to-attributes contexts $\mathbf{K}=\left\{\mathcal{K}_{i}\right\}_{i=1, \ldots, n}$ and a set of objects-to-objects binary relations $\mathbf{R}=\left\{r_{k}\right\}_{k=1, \ldots, m}$. Here, a relation $r \in R$ links two object sets from two contexts, i.e., there are $i_{1}, i_{2} \in\{1, \ldots, n\}$ (possibly $i_{1}=i_{2}$ ) such that $r \subseteq O_{i_{1}} \times O_{i_{2}}$. Both contexts from $\mathbf{K}$ and relations from $\mathbf{R}$ are introduced as cross-tables,[11].

Definition 2: [11] (Relational Context Family (RCF)) An $\mathrm{RCF}$ is a pair $(\mathbf{K}, \mathbf{R})$ where:

$$
\begin{aligned}
& \text { - } \mathbf{K}=\left\{\mathcal{K}_{i}\right\}_{i=1, \ldots, n} \text { is a set of contexts } \mathcal{K}_{i}=\left(O_{i}, A_{i}, I_{i}\right) \\
& \text { and } \\
& \text { - } \mathbf{R}=\left\{r_{k}\right\}_{k=1, \ldots, m} \text { is a set of relations } r_{k} \text { where } \\
& \quad r_{k} \subseteq O_{i_{1}} \times O_{i_{2}} \text { for some } i_{1}, i_{2} \in 1, \ldots, n .
\end{aligned}
$$

Cluster analysis partition data into sets (clusters) sharing common properties, [2]. A frequently used tool in cluster analysis is a dissimilarity function $d$ on a set of objects $E$, measuring the degree of dissemblance between the elements in $E$, [2].

\section{SELECTIONS}

Students are first properly introduced to the meaning of learning styles and are afterwards suggested to express their preferences via web based questionnaires.

We consider four groups of students formed according to gender and work experience. Criteria used under refinement order are based on learning styles models as in [4] and [5].

These four groups of students can be placed in seven sets due to application of one of the fore-mentioned criteria. Each of these seven sets has two subsets with $1+3$ or $2+2$ items in a subset.

After employing two of those criteria we obtain six sets following the refinement order. These six sets contain three subsets each with one or two items in a subset. All of them are placed in the 3rd row of the lattice in Fig. 1. In any of the six sets there is a couple of indiscernible elements (groups). Splitting these couples requires enforcement of yet another criterion. Set-valued functions developed in RCA are well suited for extracting knowledge from sets of students formed at different time periods.

Whether all criteria are to be applied or just some of them is up to a system modeling team. At the same time lattices as in Fig. 1 obtained from disjoint sets of students can be connected via RCA for extracting additional knowledge. The technical side of such processes is well explained in [11].

Four teaching styles described in [19] are ranked according to students' preferences as in permutograph in Fig. 2. The numbers in 1, 2, 3, 4 in Fig. 2 represent the four commonly understood teaching styles, i. e. formal authority (1), demonstrator (2), facilitator (3), and delegator (4). Teaching styles vary from topic to topic and students feedback can be followed by studying their responses, delivered via web

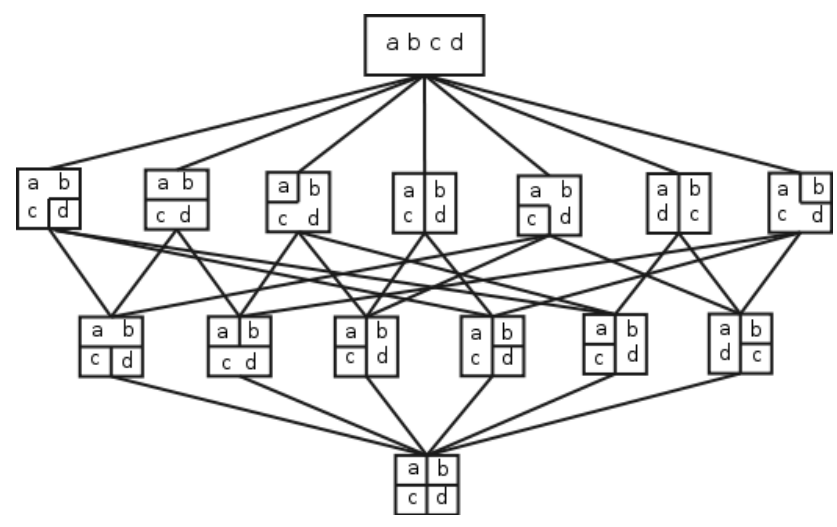

Fig. 1: Lattice of partitions

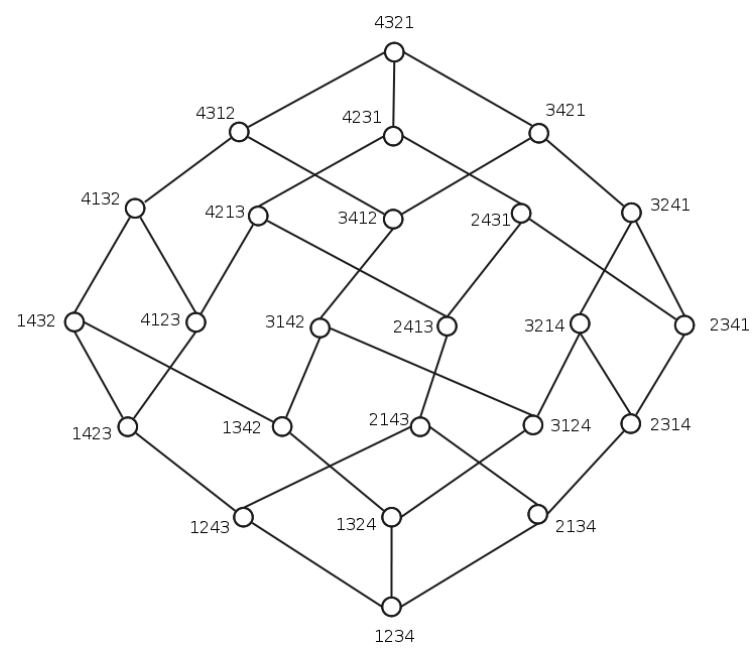

Fig. 2: Permutograph

based questionnaires. All possible orderings are summarized in Fig. 2, where two orderings connected by a strait line differ in positioning of two neighbor elements. This can be used while adjusting current teaching of new topics as well as performing further tuning of teaching the same course in the future.

Distances between vertices are applied while considering which group of users is effecting the order of preferences. Gender and age f. ex. are factors with a significant implication on preference orderings. This is to be incorporated in corresponding recommending processes. If users supply that type of information they would receive recommendations based on data from users with similar initial characteristics. If users do not provide such information they would receive recommendations based on the total collected data.

As an example about students' preferences one can look at the usual dilemma about orders in which problems are delivered by a course instructor: "learning how to apply a skill benefits more from blocked problem orders" while "learning when to apply a skill benefits more from interleaved problem orders", [16].

Another example is related to finding the degree to which students' preferences effect their progress in two consecutive 


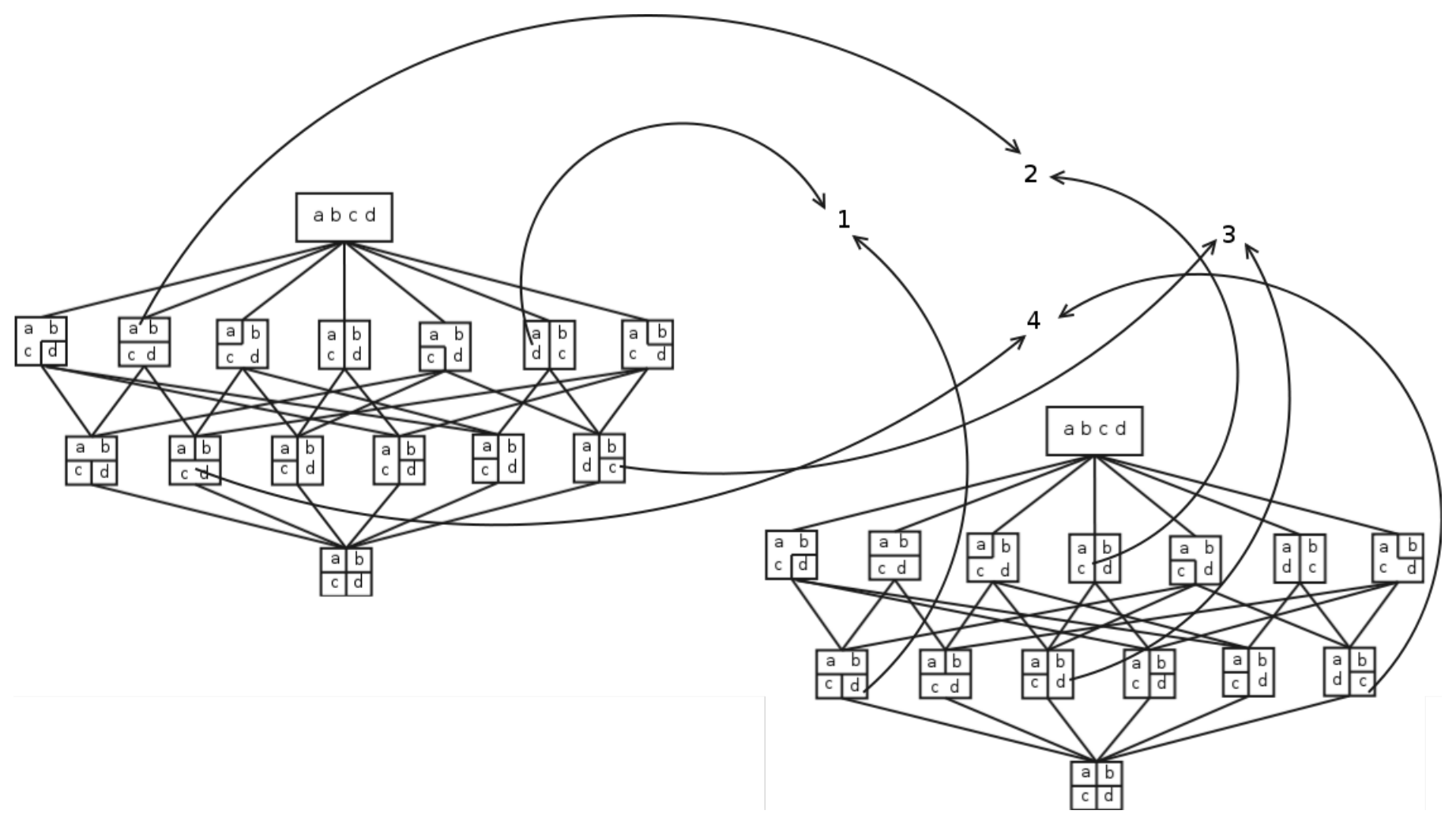

Fig. 3: Learning styles and preferences to teaching styles of two student groups

subjects when one of them is a prerequisite to the other. In a similar fashion one can work with related topics within a subject.

Distances between preferences can also be used to form clusters by joining existing clusters if they are within a predefined geodesic distance from a particular node, or creating new clusters with elements not within the geodesic distance. Once the clusters are formed an analysis of the reasons for their formations is to be performed.

Relational concept analysis is to be further applied for drawing conclusions about teaching different groups of students. Students groups, their learning styles and lectures teaching styles are to be collected in an information table as in [11]. The derived Hasse diagrams show correlations between learning styles and teaching styles, Fig. 3.

\section{CONCLUSION}

There is no doubt about the existence of dependencies between students learning styles and lecturers teaching styles. Additional research has to be carried out in order to come up with meaningful recommendations to future instructors. Once a need for further tuning of a lecturer's teaching is established, additional efforts have to made for finding out what exactly has to be done. Both permutographs and relational concept analysis lend themselves very well to exploring compatibility between learning and teaching styles.

\section{REFERENCES}

[1] K. R. Barrett, B. L. Bower and N. C. Donovan, Teaching Styles of Community College Instructors, American Journal of Distance Education, vol. 21(1), pp. 37-49, 2007.

[2] N. Caspard, B. Leclerc, and B. Monjardet, Finite Ordered Sets Concepts, Results and Uses, Cambridge University Press, 2012.

[3] B. A. Davey and H. A. Priestley, Introduction to lattices and order, Cambridge University Press, Cambridge, 2005.

[4] R. M. Felder and L. K. Silverman, Learning Styles and Teaching Styles in Engineering Education, Engineering Education, vol. 78 (7), pp. 674681, 1988.

[5] R. M. Felder, Reaching the Second Tier: Learning and Teaching Styles in College Science Education, Journal of College Science Teaching, vol. 23(5), pp. 286-290, 1993.

[6] R. M. Felder, Matters of style, ASEE Prism, vol. 6(4), pp. 18-23, 1996.

[7] R. M. Felder and J. Spurlin, Applications, reliability, and validity of the index of learning styles, International Journal of Engineering Education, vol. 21(1), pp. 103-112, 2005.

[8] B. Ganter and R. Wille, Formal Concept Analysis, Springer, 1999.

[9] A. Grasha, Teaching with Style, Pittsburgh, PA: Alliance Publishers, 1996.

[10] M. R. Hacene, M. Huchard, A. Napoli, and P. Valtchev, A proposal for combining formal concept analysis and description logics for mining relational data. In: Kuznetsov, S., Schmidt, S. (eds.) Proc. of the 5th Intl. Conf. on Formal Concept Analysis (ICFCA07). LNCS, vol. 4390, pp. 51-65, 2007.

[11] M. R. Hacene, M. Huchard, A. Napoli and P. Valtchev, Relational concept analysis: mining concept lattices from multi-relational data, Ann. Math. Artif. Intell., vol. 67, pp. 81-108, 2013.

[12] N. Herrmann, The Creative Brain, Lake Lure, NC, Brain Books, 1990.

[13] M. Huchard, M. R. Hacene, C. Roume, and P. Valtchev, Relational concept discovery in structured datasets, Ann. Math. Artif. Intell, vol. 49 (1-4), pp. 39-76, 2007.

[14] M. H. McCaulley, The MBTI and Individual Pathways in Engineering Design, Engineering Education, vol. 80, pp. 537-542, 1990.

[15] D. A. Kolb, Experiential Learning: Experience as the Source of Learning and Development Englewood Cliffs, NJ, Prentice-Hall, 1984. 
[16] N. Li, W. W. Cohen, and K. R. Koedinger, Problem Order Implications for Learning Transfer, Lecture Notes in Computer Science, vol. 7315, pp. 185-194, 2012.

[17] T. A. Litzinger, H. L. Sang, J .C. Wise, and R. M. Felder, A psychometric study of the index of learning styles, Journal of Engineering Education, vol. 96(4), pp. 309-319, 2007.

[18] M. Lumsdaine and M. Lumsdaine, Thinking Preferences of Engineering Students: Implications for Curriculum Restructuring, Journal of Engineering Education, vol. 84(2), pp. 193-204, 1995.

[19] R. Wittmann-Price, M. Godshall, and L. Wilson, Certified Nurse Educator (CNE) Review Manual, Springer Publishing Company, 2 edition, 2013. 